\title{
On the neural mechanisms subserving consciousness and attention
}

\section{Catherine Tallon-Baudry*}

INSERM U975, CNRS UMR7225, Centre de Recherche de I'Institut du Cerveau et de la Moëlle épinière, Université Pierre et Marie Curie-Paris 6 UMR-S975, Paris, France

Edited by:

Jeroen J. A. Van Boxtel, University of California Los Angeles, USA

Reviewed by:

Ryota Kanai, University College

London, UK

Jessica Sänger.

Heinrich-Heine-University of

Düsseldorf, Germany

*Correspondence:

Catherine Tallon-Baudry, Centre de Recherche de I'Institut du Cerveau et de la Moëlle épinière, Université Pierre et Marie Curie-Paris, 47 Bd de

I'Hôpital, 75013 Paris, France.

e-mail: catherine.tallon-baudry@ upmc.fr
Consciousness, as described in the experimental literature, is a multi-faceted phenomenon, that impinges on other well-studied concepts such as attention and control. Do consciousness and attention refer to different aspects of the same core phenomenon, or do they correspond to distinct functions? One possibility to address this question is to examine the neural mechanisms underlying consciousness and attention. If consciousness and attention pertain to the same concept, they should rely on shared neural mechanisms. Conversely, if their underlying mechanisms are distinct, then consciousness and attention should be considered as distinct entities. This paper therefore reviews neurophysiological facts arguing in favor or against a tight relationship between consciousness and attention. Three neural mechanisms that have been associated with both attention and consciousness are examined (neural amplification, involvement of the fronto-parietal network, and oscillatory synchrony), to conclude that the commonalities between attention and consciousness at the neural level may have been overestimated. Last but not least, experiments in which both attention and consciousness were probed at the neural level point toward a dissociation between the two concepts. It therefore appears from this review that consciousness and attention rely on distinct neural properties, although they can interact at the behavioral level. It is proposed that a "cumulative influence model," in which attention and consciousness correspond to distinct neural mechanisms feeding a single decisional process leading to behavior, fits best with available neural and behavioral data. In this view, consciousness should not be considered as a top-level executive function but should rather be defined by its experiential properties.

Keywords: attention, consciousness, vision, imaging, MEG, electrophysiology, fMRI, review

\section{INTRODUCTION}

Attention and consciousness have traditionally been considered as closely related. In 1890, William James famously wrote "Everyone knows what attention is. It is the taking possession by the mind, in clear and vivid form, of one out of what seem several simultaneously possible objects or trains of thought. Focalization, concentration, of consciousness are of its essence" (James, 1890). About a 100 years later, it was argued (Posner, 1994) that "an understanding of consciousness must rest on an appreciation of the brain networks that subserve attention." In this view, attention and consciousness reflect related concepts, much as temperature and heat. The idea that attention acts as a gateway for consciousness has been formalized in influential theories of consciousness (Baars, 1997; Dehaene and Naccache, 2001; Dennett, 2001): those events that enter consciousness are those that have been selected and amplified by attention.

Before examining whether this intuitive view on the intrinsic link between attention and awareness fits with experimental evidence, it is worth reminding why it is important to uncover the link between attention and consciousness. First, from a purely scientific point of view, one cannot confuse intuition with evidence. We do have the intuition that the sun revolves around the earth, but this intuition proved to be incorrect in the face of scientific evidence. It is therefore important to submit our intuition on the intrinsic link between attention and consciousness to careful experimental scrutiny and confront theories with facts. Second, we still do not know whether consciousness has a function on its own, whether it confers an evolutionary advantage (Block, 1995; Chalmers, 1995). It is an important issue because it impinges on the definition of consciousness. Is consciousness the natural companion of all high-level cognitive functions? When consciousness disappears, as in deep sleep or in vegetative state, cognition seems to disappear as well. Besides, consciousness apparently shares limited capacities with attention and working memory. On the other hand, consciousness could be characterized by its experiential properties, rather than by its accompanying cognitive abilities (Block, 2007). Probing the nature of the links between the cognitive function "attention" and consciousness therefore taps right into the debate on the definition of consciousness: if consciousness is intrinsically related to attention, then its functional role and evolutionary advantage should pertain to executive functions. Alternatively if attention and consciousness are distinct, then consciousness should no longer be considered as an executive function, but be defined by its experiential properties. Although attention and consciousness are notoriously ill-defined concepts, some operational definitions are commonly accepted: attention is 
manipulated when a relevant aspect of the stimulus (i.e., location, color, direction of motion, etc.) is specified beforehand to the subject, consciousness is measured when the subject reports seeing or hearing something (note that I consider here mainly sensory consciousness, leaving aside the issues of self-consciousness and volition). I will rely on those operational definitions in the following of the paper, to analyze how neuroimaging results relying on those definitions can shed light on the links between attention and awareness, and, in turn, can help us to refine the theoretical definitions of those two concepts.

There are many different ways the links between attention and consciousness can be studied. Numerous behavioral findings, not extensively reviewed here, suggest a strong link: attention can facilitate detection (Solomon, 2004) and alter the subjective appearance of stimuli (Carrasco et al., 2004). Conversely, in the absence of attention, salient stimuli may not be reported by the subjects, as in inattentional blindness (Mack and Rock, 1998), change blindness (Simons and Levin, 1997), or during the attentional blink (Shapiro et al., 1997). However a growing number of elegant behavioral manipulations in patients (Kentridge et al., 1999, 2004) and normal participants (Sumner et al., 2006; Kentridge et al., 2008; Van Boxtel et al., 2010b; Faivre and Kouider, 2011) show that attention and consciousness can sometimes be distinguished, within a disputed theoretical framework (Lamme, 2003; Van Boxtel et al., 2010a; Cohen and Dennett, 2011). I will focus here on the neural mechanisms subserving attention and consciousness. The rationale is quite simple: if attention and consciousness functionally and conceptually overlap, they should share common neural mechanisms. Conversely, if attention and consciousness turn out to rely on independent neural mechanisms, then they probably reflect distinct concepts and functions. Let us consider an analogy: looking at a contemporary painting can be a disconcerting experience. To see better, both a powerful lamp and the explanations of an art critic can be extremely useful. The means employed to see better - speech and light - fundamentally differ, and should therefore not be confused. Note that this analogy does not imply that speech and light are analogous to awareness and attention, but rather that seeing better, in other words the end-product of both attention and awareness, can be achieved by different means.

I will first present how the links between attention and consciousness can be conceived at the neural level, and then review and discuss three points of apparent convergence between the neural mechanisms involved in attention and consciousness. The first one is sensory amplification: for a stimulus to reach awareness, enough sensory activation must be present. Because attention selectively amplifies sensory inputs, it could foster consciousness. Second, attention is controlled by activity in the fronto-parietal network, that has been repeatedly found to correlate with consciousness reports. Last, oscillatory neural synchrony has been proposed to play a role in both attention and consciousness. I will then review those imaging experiments that simultaneously manipulated attention and measured consciousness.

\section{HOW THE LINK BETWEEN ATTENTION AND CONSCIOUSNESS CAN BE CONCEIVED}

Figure 1 attempts at schematically formalizing how the links between attention and awareness can be conceived. It is clearly
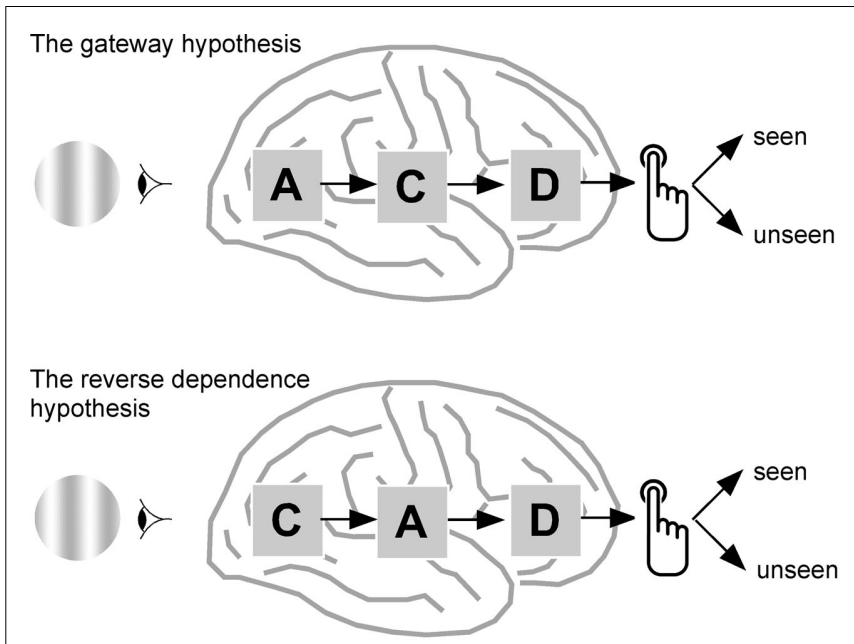

The cumulative influence hypothesis

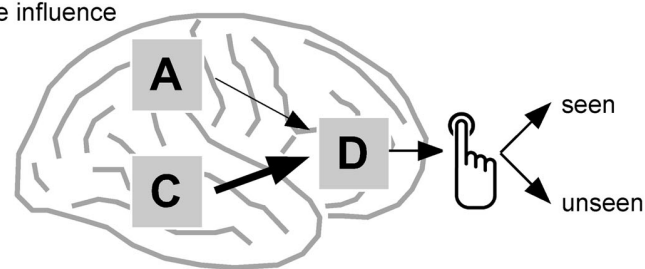

FIGURE 1 | How attention and consciousness could be related. Three options are presented, that all depend on attention-related activities, noted as $A$, consciousness-related activity, noted as $C$, and decisional process, noted as $D$, until the subject finally produces his or her behavioral report on the presence or absence of a stimulus. Top, the gateway hypothesis. In this classical view (Dehaene et al., 2006), attention facilitates consciousness, and could even be considered as necessary for consciousness to emerge. Middle, the reverse dependence hypothesis. Alternatively, whether a stimulus has been detected or not at the neural level could trigger different attentional mechanisms. Although some behavioral data could be in line with this possibility (Hsu et al., 2011), it is not directly supported by neural data so far. Bottom, the cumulative influence hypothesis. In this view, that could account for a number of imaging results, attention, and consciousness would be implemented by distinct neural mechanisms, but would both influence, although with different weights, the final report of the subject on the presence or absence of a stimulus. This hypothesis postulates the existence of a decision variable that would accumulate mainly consciousness-related neural activity, but also, to a lesser extent, attention-related neural activity. Behavioral reports based on this decision variable could therefore show an interaction between attention and consciousness, whereas neural variables could be related solely to attention and consciousness.

inspired by Lamme's influential paper (Lamme, 2003), but introduces new options and, importantly, an additional component: decision. Indeed, consciousness is experimentally studied mainly by sorting out behavioral or neural measures according to subjects' report, for instance depending on whether the subject saw a face or vase, a grating, or a blank screen. Reporting one's perceptual state implies deciding which option should be chosen. It is therefore important to incorporate the decisional step into models of consciousness. Decisional processes have been so far analyzed in the perceptual decision-making model (Smith and Ratcliff, 2004), without any explicit reference to consciousness. 
In this model, a decision variable accumulates sensory evidence until a response criteria is reached. Decision depends on the initial bias, i.e., whether the response criterion is a priori lower for one option, and on the rate of accumulation of sensory evidence. This model explains well reaction times distributions (Smith and Ratcliff, 2004), and evidence for the existence of decision variable in areas downstream to sensory regions has been obtained both in monkeys (Gold and Shadlen, 2007) and humans (Heekeren et al., 2008).

The first option is that attention is a prerequisite for awareness: those stimuli that are voluntarily attended to, or that are salient enough to attract attention, can reach consciousness and be reported. I will call this possibility the gateway model. For the sake of completeness, one should also consider the possibility that attention depends on consciousness. In other words, the type of attentional processes mobilized in a given task could depend on whether the subject is aware of the stimulus ("reverse dependence"). Last, attention and consciousness could be initially independent, but combined at a later, decisional stage leading to the final verbal report of the subject. I will call this last option the cumulative influence model. Note that in all models, when either the neural mechanisms involved in attention and consciousness are affected, the subjective report of the subject is modified. Measuring directly the neural mechanisms related to attention and consciousness may therefore prove useful to discriminate between the three hypothesis. In an experiment in which attention is manipulated and consciousness measured, if all observed neural correlates of consciousness depend on attentional manipulation, then the gateway model is likely to be the correct one. Finding distinct correlates of attention depending on whether the subject reported the stimulus or not would favor the reverse dependence model. Last, if some neural correlates of consciousness are independent from attention and some neural correlates of attention are independent from consciousness, then the cumulative influence view is more likely.

\section{NEURAL AMPLIFICATION IN ATTENTION AND CONSCIOUSNESS}

The role of attention is to prioritize incoming sensory processing to enable optimized behavioral responses given the task at hand. The main neural mechanisms associated to the attentional modulation of sensory processing are target amplification and distractor suppression. By combining these two mechanisms, sensory regions would be able to selectively amplify target-related neural signals to facilitate the transmission of target-related information further along the information processing chain (Desimone and Duncan, 1995). A huge amount of experimental evidence for target amplification in sensory regions has been obtained in the last 30 years in monkeys and humans (Desimone and Duncan, 1995; Kastner and Ungerleider, 2000; Corbetta and Shulman, 2002; Reynolds and Chelazzi, 2004; Raz and Buhle, 2006). Target enhancement can be observed in all correlates of neural activity, from firing rates (Treue, 2003; Reynolds and Chelazzi, 2004; Bisley and Goldberg, 2010) to gamma-band oscillatory synchrony (Gruber et al., 1999; Fries et al., 2001; Tallon-Baudry et al., 2005; Siegel et al., 2008), event-related potentials (Hillyard and Anllovento, 1998; Luck et al., 2000), and BOLD signal (Corbetta et al., 1990; Kastner et al., 1998). Evidence for distractor suppression has also been obtained, by showing that when two stimuli are presented in the receptive field of the neuron, the overall response of this neuron is similar to the response to the target presented alone (Moran and Desimone, 1985; Chelazzi et al., 1993; Reynolds et al., 1999). Active mechanisms of distractor suppression have also been described in humans (Luck et al., 1997; Vanduffel et al., 2000; Worden et al., 2000; Hopf et al., 2006; Thut et al., 2006; Andersen and Muller, 2010). Those results lend strong support to the biased competition model of attention (Desimone and Duncan, 1995) as well as to the idea of priority maps (Itti and Koch, 2001).

Many influential theories of consciousness posit that selective neural amplification plays a key role for an information to reach awareness. This assumption is explicit in the global workspace model (Baars, 1997; Dehaene et al., 1998), the multiple draft theory (Dennett, 1991), but is also present in the dynamic core hypothesis (Tononi and Edelman, 1998; Edelman, 2003). Competition between different inputs is central to all those models: the neural information that has been most amplified is the winner, the one that reaches consciousness (Crick and Koch, 2003). In this view, a neural correlate of consciousness is by definition an activity that is larger in response to consciously seen stimuli than to unseen stimuli. Experimentally, neural amplification is at the heart of most experimental results on consciousness: in most cases, activity in sensory regions appear to be larger for consciously seen stimuli (Tong et al., 1998; Polonsky et al., 2000; Rees et al., 2000; Dehaene et al., 2001; Vuilleumier et al., 2001; Ress and Heeger, 2003; Haynes et al., 2005; Tse et al., 2005; Hesselmann et al., 2011; Sergent et al., 2011). Note however that although consciousness has been associated most often with response amplification, response attenuation has also been described in humans (Melloni et al., 2011). In monkey area V4 in a binocular rivalry paradigm, single neuron activity can either increase or decrease before the animal reports perceiving the cell's preferred orientation (Leopold and Logothetis, 1996), suggesting that both response enhancement and response suppression can be informative. Despite those two results, response amplification is most often considered to play a crucial role in consciousness. It could be tempting to infer that enhanced sensory responses to seen stimuli are due to a mechanism of neural amplification akin to the one used by attention. This is all the more true that sensory activities correlating with consciousness have been observed between 100 and $200 \mathrm{~ms}$ using stimuli at detection threshold (Pins and Ffytche, 2003) or a modified rivalry paradigm (Roeber et al., 2008), a latency range that is typically affected by attention (Luck et al., 2000).

To what extent does the parallelism between sensory responses amplified by attention and sensory responses reaching consciousness hold true? Behaviorally, spatial attention is considered to facilitate detection by enhancing perceived contrast (Carrasco, 2011), although there is some ongoing controversies (Solomon, 2004; Schneider and Komlos, 2008). This proposal seems to be in line with the enhanced responses to attended stimuli in visual cortices, but this convergence between behavioral studies and physiological recordings may be only superficial. Indeed, increasing the physical contrast of the stimulus induces a robust latency shift of the neural sensory response, with high-contrast grating peaking 30-40 ms earlier in monkey area V1 (Gawne et al., 1996). 
Surprisingly, there is no available evidence that attended stimuli, that are supposed to be neurally encoded with an enhanced contrast leading to detection, give rise to faster responses than unattended stimuli. In humans, the best-studied attentional modulation (Hillyard and Anllovento, 1998; Luck et al., 2000) is the amplitude enhancement by spatial attention of the so-called P1, a wave of activity that occurs around $100 \mathrm{~ms}$ in early extra-striate areas (Di Russo et al., 2002). P1 amplitude enhancement by spatial attention is not accompanied by a shortening of its latency. Magneto-encephalographic data, that have a better spatial resolution than EEG data, revealed a spatially fine-grained attentional suppression/enhancement of the P1 amplitude but nevertheless failed to reveal a shortening of latency by spatial attention (Hopf et al., 2006). The only report of a P1 latency shortening has been obtained with eye-gaze cues (Schuller and Rossion, 2001, 2004). Spatial attention could potentially induce latency shifts coupled with amplitude increases at longer latencies only, after $200 \mathrm{~ms}$ (Noguchi et al., 2007). A direct comparison of the effects of contrast and of spatial attention has been performed in monkey area V4 (Lee et al., 2007). Both attention and contrast enhancement affected the magnitude of single cell responses. However, attention did not change the response latency, while contrast did. It has even been recently suggested that visual attention and stimulus contrast rely on separable neural codes in monkey area V1 (Pooresmaeili et al., 2010). To conclude, the neural mechanisms used by attention are not directly equivalent to contrast enhancement: there may be different ways of coding saliency at the neural level. This conclusion does not in itself allow to distinguish between the three hypothesis described in Figure 1, but it leaves open the possibility that the same final behavioral output, here enhanced detection, may be achieved by distinct neural mechanisms.

\section{INVOLVEMENT OF THE FRONTO-PARIETAL NETWORK IN ATTENTION AND CONSCIOUSNESS}

Attention operates in sensory regions, but the top-down control of voluntary or goal-directed attention largely relies on parietal and frontal cortices in humans (Corbetta and Shulman, 2002; Bressler et al., 2008; Corbetta et al., 2008; Greenberg et al., 2010) and monkeys (Bisley and Goldberg, 2003; Reynolds and Chelazzi, 2004; Buschman and Miller, 2007; Ekstrom et al., 2008). In parallel, parietal and frontal correlates of awareness have been often reported (Rees et al., 2002). Activity in those regions is abnormal in altered states of consciousness, such as in vegetative patients (Laureys, 2005) or during generalized epileptic seizures accompanied by a loss of consciousness (Blumenfeld et al., 2003). Frontal regions are also the first areas to deactivate when falling asleep and the last ones to reactivate after awakening (Hobson and Pace-Schott, 2002). Imaging studies of consciousness repeatedly underlined the role of the dorsolateral prefrontal cortex (Sahraie et al., 1997; Lumer et al., 1998; Beck et al., 2001; Lau and Passingham, 2006), parietal regions (Kleinschmidt et al., 1998; Lumer et al., 1998; Beck et al., 2001, 2006; Vuilleumier et al., 2001; Carmel et al., 2006; Hesselmann et al., 2011), the inferior frontal cortex (Lumer et al., 1998; Dehaene et al., 2001; Vuilleumier et al., 2001; Sergent et al., 2005; Carmel et al., 2006; Hesselmann et al., 2011), as well as the anterior cingulate cortex (Dehaene et al., 2001; Sergent et al., 2005; Carmel et al., 2006). In monkeys, the perceived direction of an ambiguous motion correlates with activity in the parietal region LIP (Williams et al., 2003), and correlates of detection of somatosensory stimuli at threshold are best observed in the medial premotor cortex (De Lafuente and Romo, 2005, 2006).

All the areas listed above as correlates of consciousness have also been associated with attention and control. The dorsolateral prefrontal cortex and the anterior cingulate are well known to be involved in control and performance monitoring (Macdonald et al., 2000). The dorsolateral prefrontal cortex is also an important structure for the maintenance of sensory information in memory (Constantinidis et al., 2001; Curtis and D'esposito, 2003), and could potentially participate to the attentional selection of information (Lebedev et al., 2004; Buschman and Miller, 2007). The posterior parietal cortex/anterior intraparietal sulcus (IPS) region is a key structure of the dorsal attentional network, while the inferior frontal region belongs to the ventral attentional network (Corbetta et al., 2008). A meta-analysis of imaging studies on attention, working memory, episodic retrieval, and consciousness (Naghavi and Nyberg, 2005) reveals a large overlap in the posterior parietal cortex, that belongs to the dorsal attentional network, and in the dorsolateral prefrontal cortex, associated to decisionmaking. From this convergence one could be tempted to deduce the existence of a central executive based on the posterior parietal cortex and dorsolateral prefrontal cortex, that would be necessary for all high-level functions. This central executive could constitute a core component of consciousness (Dehaene et al., 2006; Del Cul et al., 2009). Alternatively, fronto-parietal activations in some studies could be due to uncontrolled fluctuations of attention and/or memory affecting subjects' reports. To what extent do fronto-parietal activations correlate with consciousness per se?

First, it should be noted that not all experiments searching for the neural correlates of consciousness found a significant involvement of frontal or parietal regions (Tong et al., 1998; Tse et al., 2005). Potentially, the fronto-parietal activations observed in some consciousness studies could reflect a consequence of consciousness, rather than a cause. A stimulus that is consciously perceived can be cognitively manipulated, and therefore activate frontoparietal regions. In line with this idea, it has been recently shown that activity in the right dorsolateral prefrontal cortex, typically associated with transitions between different conscious contents, would be a consequence of perceived transitions rather than a cause (Knapen et al., 2011). However, a high-level of activity in the dorsal attentional network before stimulus onset can, depending on the experiment, either foster (Boly et al., 2007) or impair (Sadaghiani et al., 2009) the detection of stimuli at threshold. This latter finding can be understood in the framework of the cumulative influence hypothesis: attention-related activity can either positively participate, or actively inhibit, the final decision about the presence or absence of a stimulus.

Second, at least some of the fronto-parietal regions that have been associated with consciousness can be activated unconsciously. Activity in the anterior cingulate, dorsolateral prefrontal, and parietal cortices is modulated by events that are not consciously perceived (Berns et al., 1997). The IPS reacts to subliminally presented numbers (Naccache and Dehaene, 2001). The anterior cingulate cortex is activated by errors subjects were aware of as well as by those they were not aware of making (Hester 
et al., 2005), and medial prefrontal - occipital coupling is present in conscious as well as unconscious errors (Cohen et al., 2009). The dorsolateral prefrontal cortex (Lau and Passingham, 2007) and areas of the medial frontal cortex involved in the control of voluntary action (Sumner et al., 2007) participate to unconscious and involuntary control, and non-consciously triggered inhibitory control is associated with frontal brain potentials (Van Gaal et al., 2008).

Third, none of the studies listed above tried to disentangle the relative contributions of attention, control, memory, and consciousness to fronto-parietal activations. For instance, since the dorsolateral prefrontal cortex participates to the maintenance of information in short-term memory, it could appear activated in many consciousness studies: to report the presence of a stimulus, information about this stimulus has to be kept in memory until the production of the behavioral response. Besides, the same paradigm has sometimes been used to probe either attention or consciousness, thereby implying that the same neural structures appear, by definition, as a correlate of both attention and consciousness. For instance, the attentional blink paradigm has been used to identify neural correlates of consciousness (Sergent et al., 2005; Kranczioch et al., 2007) or to probe the temporal limitations of attention (Husain et al., 1997; Gross et al., 2004). As a result, the parietal involvement common to all these studies could refer to either attention or consciousness.

In the light of those three lines of arguments, the fronto-parietal network contribution to consciousness should be re-evaluated: fronto-parietal activations appear neither necessary nor sufficient for consciousness, and/or could reflect other functions such as attention and memory. However it should be noted that the term "fronto-parietal" is often used to refer to a vast ensemble of loosely defined regions, supporting "high-level" functions in general. It may be necessary to be much more specific. For instance, different subregions of the right superior parietal lobule appear to play distinct roles on perceptual fluctuations in binocular rivalry (Kanai et al., 2011). Applying TMS stimulation over right parietal regions can lead to a shortening (Carmel et al., 2010) or a lengthening (Kanai et al., 2010; Zaretskaya et al., 2010) of dominance durations in binocular rivalry, depending on whether TMS stimulation is applied online or offline whether the stimulated sites are more anterior or posterior. Last, to make the story even more complex, the frontal lobes have been repeatedly associated with a hierarchical organization of cognitive control (Koechlin et al., 2003; Botvinick, 2008; Badre and D'esposito, 2009), but those models are essentially mute on consciousness: so far, understanding the frontal lobe functions did not require to take consciousness into account.

\section{OSCILLATORY SYNCHRONY}

There is a strong consensus in the literature that consciousness is a distributed process, involving the coordination of neural activity across a number of cortical regions. Oscillatory synchrony is considered as a neural mechanism that could flexibly coordinate activity within and between neural populations, in a taskdependent manner (Singer and Gray, 1995). Schematically, two neural groups, that encode distinct aspects of the stimulus for instance in their rate code, may temporarily signal to each other that they are working on related pieces of information by synchronizing their activity at the population level. Oscillatory synchrony was therefore quickly identified as a potential neural mechanism involved in the emergence of consciousness (Engel and Singer, 2001).

Experimentally, both gamma $(\sim 30-90 \mathrm{~Hz})$ and beta $(\sim 15-$ $30 \mathrm{~Hz}$ ) bands oscillatory synchrony have been linked to visual consciousness. In humans, stimuli at threshold elicit gamma-band $(30-100 \mathrm{~Hz})$ oscillations in posterior regions only when they are consciously perceived (Schurger et al., 2008; Wyart and TallonBaudry, 2008, 2009; Luo et al., 2009), and independently from objective performance (Schurger et al., 2006). In masking paradigms, word visibility is associated with enhanced long-range synchronization in the gamma (Melloni et al., 2007) or beta (Gaillard et al., 2009) range. In conditions of bistable perception, perceptual transitions are preceded and accompanied by increased gamma-band oscillatory synchrony (Doesburg et al., 2005) and by a modulation of beta-range oscillatory synchrony in a network comprising the frontal eye fields, posterior parietal cortices, lateral occipital regions, and occipital pole (Hipp et al., 2011). Failure to report the second target in the attentional blink paradigm correlates with decreased fronto-parietal beta synchrony (Gross et al., 2004). In monkeys, target visibility manipulated by flash suppression is characterized by increased gamma-band oscillations in area $\mathrm{V} 4$ and reduced alpha $(8-12 \mathrm{~Hz})$ and beta suppressions in areas $\mathrm{V} 1, \mathrm{~V} 2$, and $\mathrm{V} 4$, while spiking activity is almost unchanged (Wilke et al., 2006). The link between gamma and beta-band oscillatory synchrony and consciousness is of course not confined to the visual modality. For instance, nociceptive somatosensory stimuli around pain threshold elicit gamma-band oscillations in primary somatosensory cortex whose amplitude is tightly related to subjective pain ratings (Gross et al., 2007).

In parallel to this role in establishing the neural cooperativity thought to be necessary for consciousness to emerge, oscillatory synchrony could also be used to set up a selective filter and therefore be a core component of attentional processes (Womelsdorf and Fries, 2007). Neurons are highly sensitive to the temporal structure of incoming inputs. If a neuron receives inputs within a brief time window, it is much more likely to fire in response to those inputs and transmit information further downstream than if the inputs are dispersed in time. Because of its temporal structure, oscillatory synchrony imposes windows of increased or decreased excitability (Steriade et al., 1993; Buzsaki and Draguhn, 2004) that can facilitate the transfer of information between two neural populations (Fries, 2005). Let us consider two structures, A and $\mathrm{B}$, that compete for transmitting information to a target area $\mathrm{T}$ further along the processing chain. If $\mathrm{A}$ and $\mathrm{T}$ are synchronized but not $\mathrm{B}$ and $\mathrm{T}$, then $\mathrm{A}$ will win the competition over $\mathrm{B}$ to get its information transmitted to $\mathrm{T}$. This represents an elegant way of implementing an attentional filter, that can be used by both bottom-up and top-down attention. There is clear experimental evidence that selective attention enhances gamma-band oscillatory synchrony, in monkey area V4 (Fries et al., 2001), in human scalp EEG (Tallon-Baudry et al., 1997; Gruber et al., 1999), or MEG (Bauer et al., 2006; Vidal et al., 2006) data, as well as in intracranial recordings (Tallon-Baudry et al., 2005; Engell and Mccarthy, 2010). Importantly, the strength of gamma-band synchronization 
in monkey area V4 predicts behavioral response times (Womelsdorf et al., 2006). There is also growing evidence that oscillatory synchrony plays an important role in the control of top-down attention. Indeed, during attentional deployment, oscillatory synchrony increases between sensory regions and frontal and parietal regions, both in humans (Doesburg et al., 2008; Siegel et al., 2008) and monkeys (Buschman and Miller, 2007; Gregoriou et al., 2009).

The fact that the same neural mechanism is involved in both attention and consciousness could suggest that the two functions are intrinsically linked. Alternatively, oscillatory synchrony could be seen as a population code, that can be used by any cognitive function - much as spikes constitute the core signaling mechanism at the single neuron level. For instance, gamma-band oscillatory synchrony is known to be involved not only in attention and consciousness, but also in feature binding, memory, and learning (Tallon-Baudry and Bertrand, 1999; Jensen et al., 2007; Fries, 2009; Tallon-Baudry, 2009). It recently appeared that when distinct cognitive processes are simultaneously active, gamma-band oscillations are elicited in distinct, narrow frequency bands (Vidal et al., 2006; Schurger et al., 2008; Wyart and Tallon-Baudry, 2008; Chaumon et al., 2009). Oscillatory synchrony is now considered as an essential population code that takes advantage of neurons fine temporal tuning, not a specific marker of a given cognitive function (Jensen et al., 2007; Fries, 2009; Tallon-Baudry, 2009).

\section{PROBING ATTENTION AND CONSCIOUSNESS SIMULTANEOUSLY AT THE NEURAL LEVEL}

As underlined above, the apparent convergence between the neural correlates of attention and awareness is mainly based on experiments that either manipulated attention or measured consciousness. However, the two concepts often overlap in those experiments - for instance, is attention or consciousness probed in the attentional blink paradigm? To address more thoroughly the issue of the link between attention and consciousness, some studies attempted at manipulating attention while measuring consciousness.

Several EEG studies convincingly demonstrated that attentional mechanisms can be triggered by attentional cues that do not reach consciousness. The N2pc is a lateralized evoked component that reflects the orienting of spatial attention. It is observed between 200 and $300 \mathrm{~ms}$ after stimulus onset, over the hemisphere contralateral to the attended location. Targets rendered invisible by object-substitution masking elicit an N2pc, thereby demonstrating that attention can be attracted by stimuli that cannot be accurately reported (Woodman and Luck, 2003). In line with this idea, source modeling of EEG data reveals that seen and unseen attentional cues are initially processed in the same manner along the dorsal stream (Babiloni et al., 2006). Attention can also modulate the neural processing of stimuli that do not reach consciousness, from $200 \mathrm{~ms}$ after stimulus onset for spatial attention (Koivisto and Revonsuo, 2007 ) to 400-600 ms for temporal attention (Kiefer and Brendel, 2006). Conversely, early differences between seen and unseen stimulus, before $200 \mathrm{~ms}$, can be independent from the attentional status of the stimulus (Koivisto et al., 2006; Boehler et al., 2008; Koivisto and Revonsuo, 2008). Altogether, these results suggest that attention and consciousness can operate via a least partly independent mechanisms.
The possibility that spatial attention and visual awareness rely on at least partly independent mechanisms was directly tested in an experiment comparing neural responses to stimuli that were physically strictly identical, but that could be consciously perceived or not and attended or not, on a trial-by-trial basis (Wyart and Tallon-Baudry, 2008). In this experiment, subjects oriented their attention according to a central cue in a typical Posner paradigm, toward faint gratings, at threshold for awareness. The factorial analysis of the magneto-encephalographic data revealed the existence of high-frequency gamma-band oscillations that were larger for attended stimuli, either seen or unseen, and the existence of low-frequency gamma-band oscillations that were larger for seen stimuli, either attended or unattended. The attentionindependent correlate of awareness was localized in the posterior lateral occipital cortex (Wyart and Tallon-Baudry, 2009). The double dissociation observed in this experiment between the neural correlates of attention and consciousness is only compatible with the cumulative influence model in Figure 1. Interestingly in this experiment, although a neural correlate of visual consciousness independent from attention was identified, subjective reports were affected by spatial attention: subjects were more likely to detect the stimulus when it appeared at the attended location. A parametric analysis at the single-trial level was compatible with the existence of a decisional stage integrating both the consciousness-related and attention-related activity into the final subjective report. In other words, the results of this experiment are strongly in favor of the cumulative influence model. This model would also explain why late neural correlates of stimulus visibility (Fernandez-Duque et al., 2003; Sergent et al., 2005; Del Cul et al., 2007; Lamy et al., 2009; Genetti et al., 2010), close to the subject behavioral report, can be influenced by parameters such as attention (Koivisto et al., 2009) or confidence in one's decision (Eimer and Mazza, 2005): attention and confidence evaluation could enter the final decisional process about whether the stimulus has been experienced or not, providing additional sources of neural evidence to finally report the stimulus as seen or unseen.

There is also ample evidence that the state of the nervous system before stimulus onset can deeply influence the conscious report of the subject (Linkenkaer-Hansen et al., 2004; Palva et al., 2005; Pourtois et al., 2006; Boly et al., 2007; Hanslmayr et al., 2007; Hesselmann et al., 2008b; Monto et al., 2008; Van Dijk et al., 2008; Britz et al., 2009; Busch et al., 2009; Mathewson et al., 2009; Sadaghiani et al., 2009). Spontaneous modifications of neural activity are often attributed to fluctuations in vigilance (Linkenkaer-Hansen et al., 2004; Boly et al., 2007), gain modulation, or attention (Hanslmayr et al., 2007; Van Dijk et al., 2008), although those factors are not explicitly controlled.

According to this view, a sensory area could be in a state of high neural excitability, corresponding to a state of higher vigilance or attention, and would therefore generate a larger response when the stimulus occurs. While this explanation may hold true in some cases, it is not the only way prestimulus activity in sensory areas can influence the seen or unseen fate of a stimulus (Hesselmann et al., 2008a; Wyart and Tallon-Baudry, 2009). Indeed, a high baseline level of activity influencing the subject's behavioral report is not necessarily followed by a large response to the stimulus. The influence of baseline fluctuations thus cannot be explained only by 
an enhanced excitability leading to stronger responses to incoming stimuli. Rather, it seems that prestimulus activity in sensory regions could directly bias the decision process, by shifting the initial level of the decision variable toward one option. In other words, the sensory cortex of a subject could be biased toward judging that a stimulus is present (Wyart and Tallon-Baudry, 2009), or that the stimulus content is vase or a face (Hesselmann et al., 2008a), independently from the strength of the sensory response to the stimulus. These results show that decision-making matters in consciousness studies, and that the decision process does not fully map onto parieto-frontal regions: decisional determinants can be implemented in sensory regions as well, even before stimulus onset.

\section{CONCLUSION}

To summarize, attention does operate in sensory regions, but neural amplification by attention appears functionally distinct from the neural amplification related to consciousness: attention does not shorten response latencies, as more contrasted objects would (Lee et al., 2007), attention-related and consciousnessrelated neural activities in retinotopic areas can be dissociated (Wyart and Tallon-Baudry, 2008). There is growing evidence that events that do not reach consciousness nevertheless activate parietal and frontal regions, suggesting that they are not sufficient for consciousness to emerge. Because frontal regions are not always activated, one can even wonder whether they are necessary. An alternative possibility is that they reflect a consequence of consciousness, rather than a cause (Knapen et al., 2011). Last, oscillatory synchrony is not associated exclusively with a single process, be it feature binding, memory and learning, attention, or consciousness, but should rather be considered as a generic mechanism governing neural interactions.

The fact that there can be an independence of the sensory correlates of attention and of consciousness, together with late correlates of visibility modulated by attention and behavioral interactions between attention and consciousness, argues in favor of the cumulative influence: consciousness-related and attentionrelated neural activities would be integrated in a single decision variable. This decision variable would accumulate not only sensory evidence, as in the classical perceptual decision-making framework (Smith and Ratcliff, 2004; Gold and Shadlen, 2007; Heekeren et al., 2008), but more processed neural information related to either consciousness or attention. Whether and how such a variable is implemented remains to be determined experimentally. In any case, one should keep in mind a number of limitations of this model. First, the visual representation of the cumulative influence model as presented in Figure 1, does not capture its complexity. For instance, one could assume that a decisional process necessarily takes place in anterior regions, and at a late

\section{REFERENCES}

Andersen, S. K., and Muller, M. M. (2010). Behavioral performance follows the time course of neural facilitation and suppression during cued shifts of feature-selective attention. Proc. Natl. Acad. Sci. U.S.A. 107, 13878-13882.

time point along the processing chain. However, a decisional bias can be implemented in sensory regions and be already present before stimulus onset (Hesselmann et al., 2008a; Wyart and TallonBaudry, 2009). Second, the arguments developed in this paper are based on experimental results obtained in fMRI as well as MEG-EEG studies. One should keep in mind that the relationship between the BOLD signal and electrophysiological data is not well established yet (Logothetis, 2003), and that the different measures sometimes provide inconsistent results (Buracas and Boynton, 2007). Third, there are many different types of attention - space-based or feature-based attention, divided or selective attention, top-down and stimulus-driven attention, endogenous or exogenous spatial attention. There is already good evidence that different forms of attention rely on different networks (Corbetta and Shulman, 2002; Chica et al., 2011a) or different forms of neural communication (Buschman and Miller, 2007). Because the different types of attention are implemented differently, it is likely that they interact differently with awareness (Chica et al., 2011b; Hsu et al., 2011).

Even if the cumulative influence hypothesis has its limitations, it is so far the model that fits best with experimental data. Interestingly this model points toward the existence of a sensory neural activity related to consciousness, uncontaminated by other cognitive processes such as attention. Such an activity could potentially be very close to the immediate subjective experience of the subject. This is reminiscent of the idea of phenomenal awareness, that could be distinct from cognitive access (Block, 2007). Experimentally, the only possibility to study consciousness is to rely on the subject's final subjective report, that relies on a complex decisional process. It is therefore all the more interesting that neural data sorted according to this integrated subjective report should point toward the existence of an activity in upper visual areas uncontaminated by attention (Wyart and Tallon-Baudry, 2008) that could potentially be directly related with phenomenal consciousness (Hesselmann et al., 2011). It therefore seems that consciousness can be distinguished from accompanying cognitive functions at the neural level. It still remains to be determined what is the advantage, from a functional or evolutionary perspective, of having two amplification systems, one related to consciousness and the other to attention, and to what extent the nature of the decisional process is modified by consciousness-related entries. In particular, is it because of consciousness-related inputs that a capacity-limited cognitive bottleneck appears? Answering those questions would provide us with important clues about the still elusive functional role of consciousness.

\section{ACKNOWLEDGMENTS}

I thank Florence Campana, Claire Sergent, and Valentin Wyart for useful discussions.

and parieto-occipital areas: a highresolution eeg study. Cereb. Cortex 16, 37-46.

Badre, D., and D'esposito, M. (2009). Is the rostro-caudal axis of the frontal lobe hierarchical? Nat. Rev. Neurosci. 10, 659-669.
Bauer, M., Oostenveld, R., Peeters, M., and Fries, P. (2006). Tactile spatial attention enhances gamma-band activity in somatosensory cortex and reduces low-frequency activity in parietooccipital areas. J. Neurosci. 26, 490-501. 
Beck, D. M., Muggleton, N., Walsh, V., and Lavie, N. (2006). Right parietal cortex plays a critical role in change blindness. Cereb. Cortex 16, 712-717.

Beck, D. M., Rees, G., Frith, C. D., and Lavie, N. (2001). Neural correlates of change detection and change blindness. Nat. Neurosci. 4, 645-650.

Berns, G. S., Cohen, J. D., and Mintun, M. A. (1997). Brain regions responsive to novelty in the absence of awareness. Science 276, 1272-1275.

Bisley, J. W., and Goldberg, M. E. (2003). Neuronal activity in the lateral intraparietal area and spatial attention. Science 299, 81-86.

Bisley, J. W., and Goldberg, M. E. (2010). Attention, intention, and priority in the parietal lobe. Annu. Rev. Neurosci. 33, 1-21.

Block, N. (1995). On a confusion about a function of consciousness. Behav. Brain Res. 18, 227-287.

Block, N. (2007). Consciousness, accessibility, and the mesh between psychology and neuroscience. Behav. Brain Sci. 30, 481-499; discussion 499-548.

Blumenfeld, H., Westerveld, M., Ostroff, R. B., Vanderhill, S. D., Freeman, J., Necochea, A., Uranga, P., Tanhehco, T., Smith, A., Seibyl, J. P., Stokking, R., Studholme, C., Spencer, S. S., and Zubal, I. G. (2003). Selective frontal, parietal, and temporal networks in generalized seizures. Neuroimage 19, 1556-1566.

Boehler, C. N., Schoenfeld, M. A., Heinze, H. J., and Hopf, J. M. (2008). Rapid recurrent processing gates awareness in primary visual cortex. Proc. Natl. Acad. Sci. U.S.A. 105, 8742-8747.

Boly, M., Balteau, E., Schnakers, C., Degueldre, C., Moonen, G., Luxen, A., Phillips, C., Peigneux, P., Maquet, P., and Laureys, S. (2007). Baseline brain activity fluctuations predict somatosensory perception in humans. Proc. Natl. Acad. Sci. U.S.A. 104, 12187-12192.

Botvinick, M. M. (2008). Hierarchical models of behavior and prefrontal function. Trends Cogn. Sci. (Regul. Ed.) 12, 201-208.

Bressler, S. L., Tang, W., Sylvester, C. M., Shulman, G. L., and Corbetta, M. (2008). Top-down control of human visual cortex by frontal and parietal cortex in anticipatory visual spatial attention. J. Neurosci. 28, 10056-10061.

Britz, J., Landis, T., and Michel, C. M. (2009). Right parietal brain activity precedes perceptual alternation of bistable stimuli. Cereb. Cortex 19, 55-65.
Buracas, G. T., and Boynton, G. M. (2007). The effect of spatial attention on contrast response functions in human visual cortex. J. Neurosci. 27, 93-97.

Busch, N. A., Dubois, J., and Vanrullen, R. (2009). The phase of ongoing EEG oscillations predicts visual perception. J. Neurosci. 29, 7869-7876.

Buschman, T. J., and Miller, E. K. (2007). Top-down versus bottom-up control of attention in the prefrontal and posterior parietal cortices. Science 315, 1860-1862.

Buzsaki, G., and Draguhn, A. (2004). Neuronal oscillations in cortical networks. Science 304, 1926-1929.

Carmel, D., Lavie, N., and Rees, G. (2006). Conscious awareness of flicker in humans involves frontal and parietal cortex. Curr. Biol. 16, 907-911.

Carmel, D., Walsh, V., Lavie, N., and Rees, G. (2010). Right parietal TMS shortens dominance durations in binocular rivalry. Curr. Biol. 20, R799-R800.

Carrasco, M. (2011). Visual attention: the past 25 years. Vision Res. 51, 1484-1525.

Carrasco, M., Ling, S., and Read, S. (2004). Attention alters appearance. Nat. Neurosci. 7, 308-313.

Chalmers, D. J. (1995). Facing up to the problem of consciousness. J. Conscious. Stud. 2, 200-219.

Chaumon, M., Schwartz, D., and TallonBaudry, C. (2009). Unconscious learning versus visual perception: dissociable roles for gamma oscillations revealed in MEG. J. Cogn. Neurosci. 21, 2287-2299.

Chelazzi, L., Miller, E. K., Duncan, J., and Desimone, R. (1993). A neural basis for visual search in inferior temporal cortex. Nature 363, 345-347.

Chica, A. B., Bartolomeo, P., and ValeroCabre, A. (2011a). Dorsal and ventral parietal contributions to spatial orienting in the human brain. $J$. Neurosci. 31, 8143-8149.

Chica, A. B., Lasaponara, S., Chanes, L., Valero-Cabre, A., Doricchi, F., Lupianez, J., and Bartolomeo, P. (2011b). Spatial attention and conscious perception: the role of endogenous and exogenous orienting. Atten. Percept. Psychophys. 73, 1065-1081.

Cohen, M. A., and Dennett, D. C. (2011). Consciousness cannot be separated from function. Trends Cogn. Sci. (Regul. Ed.) 15, 358-364.

Cohen, M. X., Van Gaal, S., Ridderinkhof, K. R., and Lamme, V. A. (2009). Unconscious errors enhance prefrontal-occipital oscillatory synchrony. Front. Hum. Neurosci. 3:54. doi:10.3389/neuro.09.054.2009

Constantinidis, C., Franowicz, M. N., and Goldman-Rakic, P. S. (2001). The sensory nature of mnemonic representation in the primate prefrontal cortex. Nat. Neurosci. 4 311-316.

Corbetta, M., Miezin, F. M., Dobmeyer, S., Shulman, G. L., and Petersen, S. E. (1990). Attentional modulation of neural processing of shape, color, and velocity in humans. Science 248 1556-1559.

Corbetta, M., Patel, G., and Shulman, G. L. (2008). The reorienting system of the human brain: from environment to theory of mind. Neuron 58 306-324.

Corbetta, M., and Shulman, G. L. (2002). Control of goal-directed and stimulus-driven attention in the brain. Nat. Rev. Neurosci. 3, 201-215.

Crick, F., and Koch, C. (2003). A framework for consciousness. Nat. Neurosci. 6, 119-126.

Curtis, C. E., and D'esposito, M. (2003). Persistent activity in the prefrontal cortex during working memory. Trends Cogn. Sci. (Regul. Ed.) 7 415-423.

De Lafuente, V., and Romo, R. (2005). Neuronal correlates of subjective sensory experience. Nat. Neurosci. 8 , 1698-1703.

De Lafuente, V., and Romo, R. (2006). Neural correlate of subjective sensory experience gradually builds up across cortical areas. Proc. Natl. Acad. Sci. U.S.A. 103, 14266-14271.

Dehaene, S., Changeux, J. P., Naccache, L., Sackur, J., and Sergent, C. (2006). Conscious, preconscious, and subliminal processing: a testable taxonomy. Trends Cogn. Sci. (Regul. Ed.) 10, 204-211.

Dehaene, S., Kerszberg, M., and Changeux, J. P. (1998). A neuronal model of a global workspace in effortful cognitive tasks. Proc. Natl. Acad. Sci. U.S.A. 95, 14529-14534.

Dehaene, S., and Naccache, L. (2001). Towards a cognitive neuroscience of consciousness: basic evidence and a workspace framework. Cognition 79, 1-37.

Dehaene, S., Naccache, L., Cohen, L. Le Bihan, D., Mangin, J. F., Poline, J. B., and Riviere, D. (2001). Cerebral mechanisms of word masking and unconscious repetition priming. Nat. Neurosci. 4, 752-758.

Del Cul, A., Baillet, S., and Dehaene, S. (2007). Brain dynamics underlying the nonlinear threshold for access to consciousness. PLoS Biol. 5, e260. doi:10.1371/journal.pbio.0050260
Del Cul, A., Dehaene, S., Reyes, P., Bravo, E., and Slachevsky, A. (2009). Causal role of prefrontal cortex in the threshold for access to consciousness. Brain 132, 2531-2540.

Dennett, D. (2001). Are we explaining consciousness yet? Cognition 79, 221-237.

Dennett, D. C. (1991). Consciousness Explained. Boston, MA: Little, Brown \& Co.

Desimone, R., and Duncan, J. (1995). Neural mechanisms of selective visual attention. Annu. Rev. Neurosci. 18, 193-222.

Di Russo, F., Martinez, A., Sereno, M. I., Pitzalis, S., and Hillyard, S. A. (2002). Cortical sources of the early components of the visual evoked potential. Hum. Brain Mapp. 15, 95-111.

Doesburg, S. M., Kitajo, K., and Ward, L. M. (2005). Increased gammaband synchrony precedes switching of conscious perceptual objects in binocular rivalry. Neuroreport 16 , 1139-1142.

Doesburg, S. M., Roggeveen, A. B., Kitajo, K., and Ward, L. M. (2008). Large-scale gamma-band phase synchronization and selective attention. Cereb. Cortex 18, 386-396.

Edelman, G. M. (2003). Naturalizing consciousness: a theoretical framework. Proc. Natl. Acad. Sci. U.S.A. 100, 5520-5524.

Eimer, M., and Mazza, V. (2005). Electrophysiological correlates of change detection. Psychophysiology 42, 328-342.

Ekstrom, L. B., Roelfsema, P. R., Arsenault, J. T., Bonmassar, G., and Vanduffel, W. (2008). Bottom-up dependent gating of frontal signals in early visual cortex. Science 321, 414-417.

Engel, A. K., and Singer, W. (2001). Temporal binding and the neural correlates of sensory awareness. Trends Cogn. Sci. 5, 16-25.

Engell, A. D., and Mccarthy, G. (2010). Selective attention modulates facespecific induced gamma oscillations recorded from ventral occipitotemporal cortex. J. Neurosci. 30, 8780-8786.

Faivre, N., and Kouider, S. (2011). Multi-feature objects elicit nonconscious priming despite crowding. J. Vis. 11, 1-10.

Fernandez-Duque, D., Grossi, G., Thornton, I. M., and Neville, H. J. (2003). Representation of change: separate electrophysiological markers of attention, awareness, and implicit processing. J. Cogn. Neurosci. 15, 491-507.

Fries, P. (2005). A mechanism for cognitive dynamics: neuronal communication through neuronal coherence. 
Trends Cogn. Sci. (Regul. Ed.) 9, 474-480.

Fries, P. (2009). Neuronal gamma-band synchronization as a fundamental process in cortical computation. Annu. Rev. Neurosci. 32, 209-224.

Fries, P., Reynolds, J. H., Rorie, A. E., and Desimone, R. (2001). Modulation of oscillatory neuronal synchronization by selective visual attention. Science 291, 1560-1563.

Gaillard, R., Dehaene, S., Adam, C., Clemenceau, S., Hasboun, D., Baulac, M., Cohen, L., and Naccache, L. (2009). Converging intracranial markers of conscious access. PLoS Biol. 7, e61. doi:10.1371/journal.pbio. 1000061

Gawne, T. J., Kjaer, T. W., and Richmond, B. J. (1996). Latency: another potential code for feature binding in striate cortex. J. Neurophysiol. 76, 1356-1360.

Genetti, M., Britz, J., Michel, C. M., and Pegna, A. J. (2010). An electrophysiological study of conscious visual perception using progressively degraded stimuli. J. Vis. 10, 10.

Gold, J. I., and Shadlen, M. N. (2007). The neural basis of decision making. Annu. Rev. Neurosci. 30, 535-574.

Greenberg, A. S., Esterman, M., Wilson, D., Serences, J. T., and Yantis, S. (2010). Control of spatial and feature-based attention in frontoparietal cortex. J. Neurosci. 30, 14330-14339.

Gregoriou, G. G., Gotts, S. J., Zhou, H., and Desimone, R. (2009). High-frequency, long-range coupling between prefrontal and visual cortex during attention. Science 324, 1207-1210.

Gross, J., Schmitz, F., Schnitzler, I., Kessler, K., Shapiro, K., Hommel, B., and Schnitzler, A. (2004). Modulation of long-range neural synchrony reflects temporal limitations of visual attention in humans. Proc. Natl. Acad. Sci. U.S.A. 101, 13050-13055.

Gross, J., Schnitzler, A., Timmermann, L., and Ploner, M. (2007). Gamma oscillations in human primary somatosensory cortex reflect pain perception. PLoS Biol. 5, e133. doi:10.1371/journal.pbio.0050133

Gruber, T., Muller, M. M., Keil, A., and Elbert, T. (1999). Selective visual-spatial attention alters induced gamma band responses in the human EEG. Clin. Neurophysiol. 110, 2074-2085.

Hanslmayr, S., Aslan, A., Staudigl, T., Klimesch, W., Herrmann, C. S., and Bauml, K. H. (2007). Prestimulus oscillations predict visual perception performance between and within subjects. Neuroimage 37, 1465-1473.

Haynes, J. D., Driver, J., and Rees, G. (2005). Visibility reflects dynamic changes of effective connectivity between V1 and fusiform cortex. Neuron 46, 811-821.

Heekeren, H. R., Marrett, S., and Ungerleider, L. G. (2008). The neural systems that mediate human perceptual decision making. Nat. Rev. Neurosci. 9, 467-479.

Hesselmann, G., Hebart, M., and Malach, R. (2011). Differential BOLD activity associated with subjective and objective reports during "blindsight" in normal observers. J. Neurosci. 31, 12936-12944.

Hesselmann, G., Kell, C. A., Eger, E., and Kleinschmidt, A. (2008a). Spontaneous local variations in ongoing neural activity bias perceptual decisions. Proc. Natl. Acad. Sci. U.S.A. 105, 10984-10989.

Hesselmann, G., Kell, C. A., and Kleinschmidt, A. (2008b). Ongoing activity fluctuations in hMT+ bias the perception of coherent visual motion. J. Neurosci. 28, 14481-14485.

Hester, R., Foxe, J. J., Molholm, S., Shpaner, M., and Garavan, H. (2005). Neural mechanisms involved in error processing: a comparison of errors made with and without awareness. Neuroimage 27, 602-608.

Hillyard, S. A., and Anllovento, L. (1998). Event-related brain potentials in the study of visual selective attention. Proc. Natl. Acad. Sci. U.S.A. 95, 781-787.

Hipp, J. F., Engel, A. K., and Siegel, M. (2011). Oscillatory synchronization in large-scale cortical networks predicts perception. Neuron 69, 387-396.

Hobson, J. A., and Pace-Schott, E. F. (2002). The cognitive neuroscience of sleep: neuronal systems, consciousness and learning. Nat. Rev. Neurosci. 3, 679-693.

Hopf, J. M., Boehler, C. N., Luck, S. J., Tsotsos, J. K., Heinze, H. J., and Schoenfeld, M. A. (2006). Direct neurophysiological evidence for spatial suppression surrounding the focus of attention in vision. Proc. Natl. Acad. Sci. U.S.A. 103, 1053-1058.

Hsu, S. M., George, N., Wyart, V., and Tallon-Baudry, C. (2011). Voluntary and involuntary spatial attentions interact differently with awareness. Neuropsychologia 49, 2465-2474.

Husain, M., Shapiro, K., Martin, J., and Kennard, C. (1997). Abnormal temporal dynamics of visual attention in spatial neglect patients. Nature 385, 154-156.

Itti, L., and Koch, C. (2001). Computational modelling of visual attention. Nat. Rev. Neurosci. 2, 194-203.

James, W. (1890). The Principles of Psychology. New York: Heny Holt.

Jensen, O., Kaiser, J., and Lachaux, J. P. (2007). Human gamma-frequency oscillations associated with attention and memory. Trends Neurosci. 30, 317-324.

Kanai, R., Bahrami, B., and Rees, G. (2010). Human parietal cortex structure predicts individual differences in perceptual rivalry. Curr. Biol. 20, 1626-1630.

Kanai, R., Carmel, D., Bahrami, B., and Rees, G. (2011). Structural and functional fractionation of right superior parietal cortex in bistable perception. Curr. Biol. 21, R106-R107.

Kastner, S., Deweerd, P., Desimone, R., and Ungerleider, L. C. (1998). Mechanisms of directed attention in the human extrastriate cortex as revealed by functional MRI. Science 282, 108-111.

Kastner, S., and Ungerleider, L. G. (2000). Mechanisms of visual attention in the human cortex. Annu. Rev. Neurosci. 23, 315-341.

Kentridge, R. W., Heywood, C. A., and Weiskrantz, L. (1999). Attention without awareness in blindsight. Proc. R. Soc. Lond. B 266, 1805-1811.

Kentridge, R. W., Heywood, C. A., and Weiskrantz, L. (2004). Spatial attention speeds discrimination without awareness in blindsight. Neuropsychologia 42, 831-835.

Kentridge, R. W., Nijboer, T. C., and Heywood, C. A. (2008). Attended but unseen: visual attention is not sufficient for visual awareness. Neuropsychologia 46, 864-869.

Kiefer, M., and Brendel, D. (2006). Attentional modulation of unconscious "automatic" processes: evidence from event-related potentials in a masked priming paradigm. $J$. Cogn. Neurosci. 18, 184-198.

Kleinschmidt, A., Buchel, C., Zeki, S., and Frackowiak, R. S. (1998). Human brain activity during spontaneously reversing perception of ambiguous figures. Proc. Biol. Sci. 265, 2427-2433.

Knapen, T., Brascamp, J., Pearson, J., Van Ee, R., and Blake, R. (2011). The role of frontal and parietal brain areas in bistable perception. J. Neurosci. 31, 10293-10301.

Koechlin, E., Ody, C., and Kouneiher, F. (2003). The architecture of cognitive control in the human prefrontal cortex. Science 302, 1181-1185.
Koivisto, M., Kainulainen, P., and Revonsuo, A. (2009). The relationship between awareness and attention: evidence from ERP responses. Neuropsychologia 47, 2891-2899.

Koivisto, M., and Revonsuo, A. (2007). Electrophysiological correlates of visual consciousness and selective attention. Neuroreport 18, 753-756.

Koivisto, M., and Revonsuo, A. (2008). The role of selective attention in visual awareness of stimulus features: electrophysiological studies. Cogn. Affect. Behav. Neurosci. 8, 195-210.

Koivisto, M., Revonsuo, A., and Lehtonen, M. (2006). Independence of visual awareness from the scope of attention: an electrophysiological study. Cereb. Cortex 16, 415-424.

Kranczioch, C., Debener, S., Maye, A., and Engel, A. K. (2007). Temporal dynamics of access to consciousness in the attentional blink. Neuroimage 37, 947-955.

Lamme, V. A. (2003). Why visual attention and awareness are different. Trends Cogn. Sci. (Regul. Ed.) 7, 12-18.

Lamy, D., Salti, M., and Bar-Haim, Y. (2009). Neural correlates of subjective awareness and unconscious processing: an ERP study. J. Cogn. Neurosci. 21, 1435-1446.

Lau, H. C., and Passingham, R. E. (2006). Relative blindsight in normal observers and the neural correlate of visual consciousness. Proc. Natl. Acad. Sci. U.S.A. 103, 18763-18768.

Lau, H. C., and Passingham, R. E. (2007). Unconscious activation of the cognitive control system in the human prefrontal cortex. J. Neurosci. 27, 5805-5811.

Laureys, S. (2005). The neural correlate of (un)awareness: lessons from the vegetative state. Trends Cogn. Sci. (Regul. Ed.) 9, 556-559.

Lebedev, M. A., Messinger, A., Kralik, J. D., and Wise, S. P. (2004). Representation of attended versus remembered locations in prefrontal cortex. PLoS Biol. 2, e365. doi:10.1371/journal.pbio.0020365

Lee, J., Williford, T., and Maunsell, J. H. (2007). Spatial attention and the latency of neuronal responses in macaque area V4. J. Neurosci. 27, 9632-9637.

Leopold, D. A., and Logothetis, N. K. (1996). Activity changes in early visual cortex reflect monkeys' percepts during binocular rivalry. Nature 379, 549-553.

Linkenkaer-Hansen, K., Nikulin, V. V., Palva, S., Ilmoniemi, R. J., and Palva, J. M. (2004). Prestimulus oscillations enhance psychophysical 
performance in humans. J. Neurosci. 24, 10186-10190.

Logothetis, N. K. (2003). The underpinnings of the BOLD functional magnetic resonance imaging signal. J. Neurosci. 23, 3963-3971.

Luck, S. J., Girelli, M., Mcdermott, M. T., and Ford, M. A. (1997). Bridging the gap between monkey neurophysiology and human perception: an ambiguity resolution theory of visual selective attention. Cogn. Psychol. 33, 64-87.

Luck, S. J., Woodman, G. F., and Vogel, E. K. (2000). Event-related potential studies of attention. Trends Cogn. Sci. (Regul. Ed.) 4, 432-440.

Lumer, E. D., Friston, K. J., and Rees, G. (1998). Neural correlates of perceptual rivalry in the human brain. Science 280, 1930-1933.

Luo, Q., Mitchell, D., Cheng, X., Mondillo, K., Mccaffrey, D., Holroyd, T., Carver, F., Coppola, R., and Blair, J. (2009). Visual awareness, emotion, and gamma band synchronization. Cereb. Cortex 19, 1896-1904.

Macdonald, A. W. III., Cohen, J. D., Stenger, V. A., and Carter, C. S. (2000). Dissociating the role of the dorsolateral prefrontal and anterior cingulate cortex in cognitive control. Science 288, 1835-1838.

Mack, A., and Rock, I. (1998). Inattentional Blindness. Cambridge, MA: MIT Press.

Mathewson, K. E., Gratton, G., Fabiani, M., Beck, D. M., and Ro, T. (2009). To see or not to see: prestimulus alpha phase predicts visual awareness. $J$. Neurosci. 29, 2725-2732.

Melloni, L., Molina, C., Pena, M., Torres, D., Singer, W., and Rodriguez, E. (2007). Synchronization of neural activity across cortical areas correlates with conscious perception. $J$. Neurosci. 27, 2858-2865.

Melloni, L., Schwiedrzik, C. M., Muller, N., Rodriguez, E., and Singer, W. (2011). Expectations change the signatures and timing of electrophysiological correlates of perceptual awareness. J. Neurosci. 31, 1386-1396.

Monto, S., Palva, S., Voipio, J., and Palva, J. M. (2008). Very slow EEG fluctuations predict the dynamics of stimulus detection and oscillation amplitudes in humans. J. Neurosci. 28, 8268-8272.

Moran, J., and Desimone, R. (1985). Selective attention gates visual processing in the extrastriate cortex. Science 229, 782-784.

Naccache, L., and Dehaene, S. (2001). The priming method: imaging unconscious repetition priming reveals an abstract representation of number in the parietal lobes. Cereb. Cortex 11, 966-974.

Naghavi, H. R., and Nyberg, L. (2005) Common fronto-parietal activity in attention, memory, and consciousness: shared demands on integration? Conscious. Cogn. 14, 390-425.

Noguchi, Y., Tanabe, H. C., Sadato, N., Hoshiyama, M., and Kakigi, R. (2007). Voluntary attention changes the speed of perceptual neural processing. Eur. J. Neurosci. 25, 3163-3172.

Palva, S., Linkenkaer-Hansen, K., Naatanen, R., and Palva, J. M. (2005). Early neural correlates of conscious somatosensory perception. J. Neurosci. 25, 5248-5258.

Pins, D., and Ffytche, D. (2003). The neural correlates of conscious vision. Cereb. Cortex 13, 461-474.

Polonsky, A., Blake, R., Braun, J., and Heeger, D. J. (2000). Neuronal activity in human primary visual cortex correlates with perception during binocular rivalry. Nat. Neurosci. 3, 1153-1159.

Pooresmaeili, A., Poort, J., Thiele, A., and Roelfsema, P. R. (2010). Separable codes for attention and luminance contrast in the primary visual cortex. J. Neurosci. 30, 12701-12711.

Posner, M. I. (1994). Attention: the mechanisms of consciousness. Proc. Natl. Acad. Sci. U.S.A. 91, 7398-7403.

Pourtois, G., De Pretto, M., Hauert, C. A., and Vuilleumier, P. (2006). Time course of brain activity during change blindness and change awareness: performance is predicted by neural events before change onset. $J$. Cogn. Neurosci. 18, 2108-2129.

Raz, A., and Buhle, J. (2006). Typologies of attentional networks. Nat. Rev. Neurosci. 7, 367-379.

Rees, D., Backus, B.T., and Heeger, D.J. (2000). Activity in primary visual cortex predicts performance in a visual detection task. Nat. Neurosci. 3, 1347 .

Rees, G., Kreiman, G., and Koch, C. (2002). Neural correlates of consciousness in humans. Nat. Rev. Neurosci. 3, 261-270.

Ress, D., and Heeger, D. J. (2003). Neuronal correlates of perception in early visual cortex. Nat. Neurosci. 6, 414-420.

Reynolds, J. H., and Chelazzi, L. (2004). Attentional modulation of visual processing. Annu. Rev. Neurosci. 27, 611-647.

Reynolds, J. H., Chelazzi, L., and Desimone, R. (1999). Competitive mechanisms subserve attention in macaque areas V2 and V4. J. Neurosci. 19, 1736-1753.

Roeber, U., Widmann, A., TrujilloBarreto, N. J., Herrmann, C. S., O'shea, R. P., and Schroger, E. (2008) Early correlates of visual awareness in the human brain: time and place from event-related brain potentials. J. Vis. 8, 21 21-12.

Sadaghiani, S., Hesselmann, G., and Kleinschmidt, A. (2009). Distributed and antagonistic contributions of ongoing activity fluctuations to auditory stimulus detection. J. Neurosci. 29, 13410-13417.

Sahraie, A., Weiskrantz, L., Barbur, J. L., Simmons, A., and Williams, S. C. R (1997). Pattern of neuronal activity associated with conscious and unconscious processing of visual signals. Proc. Natl. Acad. Sci. U.S.A. 94 9406-9411.

Schneider, K. A., and Komlos, M. (2008). Attention biases decisions but does not alter appearance. J. Vis. 8, $31-10$.

Schuller, A. M., and Rossion, B. (2001). Spatial attention triggered by eye gaze increases and speeds up early visual activity. Neuroreport 12 , 2381-2386.

Schuller, A. M., and Rossion, B. (2004). Perception of static eye gaze direction facilitates subsequent early visual processing. Clin. Neurophysiol. 115, 1161-1168.

Schurger, A., Cowey, A., Cohen, J. D. Treisman, A., and Tallon-Baudry, C. (2008). Distinct and independent correlates of attention and awareness in a hemianopic patient. Neuropsy chologia 46, 2189-2197.

Schurger, A., Cowey, A., and TallonBaudry, C. (2006). Induced gammaband oscillations correlate with awareness in hemianopic patient GY Neuropsychologia 44, 1796-1803.

Sergent, C., Baillet, S., and Dehaene, S. (2005). Timing of the brain events underlying access to consciousness during the attentional blink. Nat. Neurosci. 8, 1391-1400.

Sergent, C., Ruff, C. C., Barbot, A., Driver, J., and Rees, G. (2011). Topdown modulation of human early visual cortex after stimulus offset supports successful postcued report. J. Cogn. Neurosci. 23, 1921-1934.

Shapiro, K. L., Raymond, J. E., and Arnell, K. M. (1997). The attentional blink. Trends Cogn. Sci. (Regul. Ed.) 1, 291-296.

Siegel, M., Donner, T. H., Oostenveld, R., Fries, P., and Engel, A. K. (2008). Neuronal synchronization along the dorsal visual pathway reflects the focus of spatial attention. Neuron 60 , 709-719.
Simons, D. J., and Levin, D. T. (1997). Change blindness. Trends Cogn. Sci. (Regul. Ed.) 1, 261-267.

Singer, W., and Gray, C. M. (1995). Visual feature integration and the temporal correlation hypothesis. Annu. Rev. Neurosci. 18, 555-586.

Smith, P. L., and Ratcliff, R. (2004). Psychology and neurobiology of simple decisions. Trends Neurosci. 27, 161-168.

Solomon, J. A. (2004). The effect of spatial cues on visual sensitivity. Vision Res. 44, 1209-1216.

Steriade, M., Mccormick, D. A., and Sejnowski, T. J. (1993). Thalamocortical oscillations in the sleeping and aroused brain. Science 262, 679-685.

Sumner, P., Nachev, P., Morris, P., Peters, A. M., Jackson, S. R., Kennard, C., and Husain, M. (2007). Human medial frontal cortex mediates unconscious inhibition of voluntary action. Neuron 54, 697-711.

Sumner, P., Tsai, P. C., Yu, K., and Nachev, P. (2006). Attentional modulation of sensorimotor processes in the absence of perceptual awareness. Proc. Natl. Acad. Sci. U.S.A. 103, 10520-10525.

Tallon-Baudry, C. (2009). The roles of gamma-band oscillatory synchrony in human visual cognition. Front. Biosci. 14, 321-332.

Tallon-Baudry, C., and Bertrand, O. (1999). Oscillatory gamma activity in humans and its role in object representation. Trends Cogn. Sci. (Regul. Ed.) 3, 151-162.

Tallon-Baudry, C., Bertrand, O., Delpuech, C., and Pernier, J. (1997). Oscillatory gamma-band $\quad(30-70$ $\mathrm{Hz}$ ) activity induced by a visual search task in humans. J. Neurosci. 17, 722-734.

Tallon-Baudry, C., Bertrand, O., Henaff, M. A., Isnard, J., and Fischer, C. (2005). Attention modulates gamma-band oscillations differently in the human lateral occipital cortex and fusiform gyrus. Cereb. Cortex 15, 654-662.

Thut, G., Nietzel, A., Brandt, S. A., and Pascual-Leone, A. (2006). Alphaband electroencephalographic activity over occipital cortex indexes visuospatial attention bias and predicts visual target detection. J. Neurosci. 26, 9494-9502.

Tong, F., Nakayama, K., Vaughan, J. T., and Kanwisher, N. (1998). Binocular rivalry and visual awareness in human extrastriate cortex. Neuron 21, 753-759.

Tononi, G., and Edelman, G. E. (1998). Consciousness and complexity. Science 282, 1846-1851. 
Treue, S. (2003). Visual attention: the where, what, how and why of saliency. Curr. Opin. Neurobiol. 13, 428-432.

Tse, P. U., Martinez-Conde, S., Schlegel, A. A., and Macknik, S. L. (2005). Visibility, visual awareness, and visual masking of simple unattended targets are confined to areas in the occipital cortex beyond human V1/V2. Proc. Natl. Acad. Sci. U.S.A. 102, 17178-17183.

Van Boxtel, J. J., Tsuchiya, N., and Koch, C. (2010a). Consciousness and attention: on sufficiency and necessity. Front. Psychol. 1:217. doi:10.3389/fpsyg.2010.00217

Van Boxtel, J. J., Tsuchiya, N., and Koch, C. (2010b). Opposing effects of attention and consciousness on afterimages. Proc. Natl. Acad. Sci. U.S.A. 107, 8883-8888.

Van Dijk, H., Schoffelen, J. M., Oostenveld, R., and Jensen, O. (2008). Prestimulus oscillatory activity in the alpha band predicts visual discrimination ability. J. Neurosci. 28, 1816-1823.

Van Gaal, S., Ridderinkhof, K. R., Fahrenfort, J. J., Scholte, H. S., and Lamme, V. A. (2008). Frontal cortex mediates unconsciously triggered inhibitory control. J. Neurosci. 28, 8053-8062.

Vanduffel, W., Tootell, R. B. H., and Orban, G. A. (2000). Attentiondependent suppression of metabolic activity in the early stages of the macaque visual system. Cereb. Cortex 10, 109-126.

Vidal, J. R., Chaumon, M., O'regan, J. K., and Tallon-Baudry, C. (2006). Visual grouping and selective attention induce gamma-band oscillations at different frequencies in human MEG signals. J. Cogn. Neurosci. 18, 1850-1862.

Vuilleumier, P., Sagiv, N., Hazeltine, E., Poldrack, R. A., Swick, D., Rafal, R. D., and Gabrieli, J. D. E. (2001). Neural fate of seen and unseen faces in visuospatial neglect: A combined event-related functional MRI and event-related potential study. Proc. Natl. Acad. Sci. U.S.A. 98, 3495-3500.

Wilke, M., Logothetis, N. K., and Leopold, D. A. (2006). Local field potential reflects perceptual suppression in monkey visual cortex. Proc. Natl. Acad. Sci. U.S.A. 103, 17507-17512.

Williams, Z. M., Elfar, J. C., Eskandar, E. N., Toth, L. J., and Assad, J. A. (2003). Parietal activity and the perceived direction of ambiguous apparent motion. Nat. Neurosci. 6, 616-623.

Womelsdorf, T., and Fries, P. (2007). The role of neuronal synchronization in selective attention. Curr. Opin. Neurobiol. 17, 154-160.

Womelsdorf, T., Fries, P., Mitra, P. P., and Desimone, R. (2006). Gammaband synchronization in visual cortex predicts speed of change detection. Nature 439, 733-736.

Woodman, G. F., and Luck, S. J. (2003). Dissociations among attention, perception, and awareness during object-substitution masking. Psychol. Sci. 14, 605-611.

Worden, M. S., Foxe, J. J., Wang, N. and Simpson, G. V. (2000). Anticipatory biasing of visuospatial attention indexed by retinotopically specific alpha-band electroencephalography increases over occipital cortex. J. Neurosci. 20, RC63.

Wyart, V., and Tallon-Baudry, C. (2008). A neural dissociation between visual awareness and spatial attention. $J$. Neurosci. 28, 2667-2679.

Wyart, V., and Tallon-Baudry, C. (2009). How ongoing fluctuations in human visual cortex predict perceptual awareness: baseline shift versus decision bias. J. Neurosci. 29, 8715-8725.
Zaretskaya, N., Thielscher, A., Logothetis, N. K., and Bartels, A. (2010). Disrupting parietal function prolongs dominance durations in binocular rivalry. Curr. Biol. 20, 2106-2111.

Conflict of Interest Statement: The author declares that the research was conducted in the absence of any commercial or financial relationships that could be construed as a potential conflict of interest.

Received: 22 September 2011; accepted: 22 December 2011; published online: 09 January 2012.

Citation: Tallon-Baudry C (2012) On the neural mechanisms subserving consciousness and attention. Front. Psychology 2:397. doi: 10.3389/fpsyg.2011.00397

This article was submitted to Frontiers in Consciousness Research, a specialty of Frontiers in Psychology.

Copyright (c) 2012 Tallon-Baudry. This is an open-access article distributed under the terms of the Creative Commons Attribution Non Commercial License, which permits non-commercial use, distribution, and reproduction in other forums, provided the original authors and source are credited. 